\title{
MYCOTOXINS IN FODDER AND ITS IMPORTANCE ON SAFETY OF FEED AND THE HEALTH OF FARM ANIMALS: A REVIEW
}

\author{
Elena Viktorovna ULRIKH ${ }^{\star \otimes}$, and Oksana Vladimirovna SMOLOVSKAYA \\ Kuzbass State Agricultural Academy, Markovtseva Street, 5, Kemerovo, 650056, Russia \\ Email: ulrikh.e.v@mail.ru; (DoRCiD: 0000-0003-4107-7277 \\ supporting Information
}

\begin{abstract}
Diets of ruminants include grains, protein fodder, hay and grass/legumes, whole grain corn, small grains, sorghum silage and feed by-products. In addition, ruminants fed grazing feed every year or every season. All these feeds can be contaminated with exogenous metabolites of certain toxin-causing fungi. There are fewer changes in food metabolism in ruminants than in pigs and poultry, and these metabolites increase and diversify the effects of mycotoxins in ruminants. Existing data indicate that some streptoxins (Aflatoxin, Aspergillus toxin, Aspergillus A toxin, Fumonisin, and Zearalenone) and many other secondary metabolites produced by many other types of Alternaria are harmful to ruminants. Tavronic acid and 4Z-infected pyrrolidone have the greatest effect on ruminants. Aspergillus flavus produces kojic acid, cyclopyrazinic acid, or $\beta$-nitropropionic acid, and $A$. fumigatus produces gliotoxin. Pseudomonas produces mycophenolic acid, Rocfortine, PR-toxin, Marcoforthine, or Monasc (citrine and monacolin), which may be associated with feed contamination. The assessment includes information on the prevalence of mycotoxins reported over the past 15 years, with particular attention to both mycotoxins found in fodders and animal toxicology issues.
\end{abstract}

Keywords: Aflatoxin; Feed contamination; Mycotoxins; Silage; Ruminants.

\section{INTRODUCTION}

Mycotoxins are known as low-molecular-weight molecules produced by fungi that can naturally provoke toxic reactions in humans and other vertebrates (Hussein and Brasel, 2001; Conte et al., 2020; Hussain et al., 2020). These are usually very stable molecules, and the secondary metabolites of molds belong to several genera, especially Aspergillus, Fusarium, and Penicillium (Nesic et al., 2014). In addition, other genera, such as Alternaria, Chaetomium, Cladosporium, Claviceps, Diplodia, Myrothecium, Monascus, Phoma, Phomopsis, Pithomyces, Trichoderma, and Stachybotrys, also include toxinproducing species (Bryden, 2012, Vedovatto et al., 2020). Mycotoxin contamination of various agricultural products before and after harvest is a global problem. To date, about 18,000 secondary metabolites of fungi have been described worldwide, but since the 1960s, only a limited number of them have aroused scientific interest (Firduas et al., 2019). As expected, the most studied mycotoxins are documented as aflatoxin (AF), citrine, deoxynivalene (DON), aspergilline (patolo), aspergillus toxin A (OTA), equine toxin (FB), and zearalenone (ZEA) (Buckley et al., 2007; Gallo et al., 2015) and some are of the main toxins - endophytic fungi (ergot toxin and ergotamine) (Porter, 1995; Scott, 2009). Typically, the term "mold poisoning" refers to a syndrome caused by ingestion, skin contact, or inhalation of these fungal metabolites (Bennett and Klich, 2003; Meggs, 2009). When livestock ingests mycotoxins, the health effects can be severe, meaning clear signs of illness or even death. However, acute manifestations of mold poisoning are rare in farm animal (Gallo et al., 2015).

They are mainly observed in plants of Baccharis infected with endophytes (Azevedo et al., 2000; Oki et al., 2009). The consequences of mycotoxin ingestion are mostly chronic, which means a potential decrease in livestock productivity (Agriopoulou et al., 2020). This effect leads to serious economic losses due to clinically ambiguous changes in animal growth, decreased feed intake, or feed digestion, altered absorption and metabolism of nutrients, effects on the endocrine system, and suppression of the immune system (Zain, 2011; Pleadin et al., 2019). Ruminants are less sensitive to mycotoxins than non-ruminant animals because rumen microbiota and food particles in the rumen can efficiently degrade, inactivate, and bind these toxic molecules, thereby protecting animals.

\section{Objects and methods}

The object of the study was scientific publications and patents of Russian and foreign authors on the study of the effect of mycotoxins on the safety of feed and the health of farm animals. The main method was generalization. In particular, statistical and economic data on the analysis of mycotoxins, scientific principles of combating mycotoxin contamination of feed, and the results of practical research and original research on new types of mycotoxins and ways to limit their spread were analyzed in this study. 
Several reviews and data on the frequency and levels of certain mycotoxin contamination of the grain and its by-products for animal nutrition have been published since the 1970s. Currently, more than 100 countries have issued specific regulations or recommended limits, or detailed instructions to control mycotoxins in animal fodder (Medina et al., 2017). Over the past 15 years, problems have arisen related to feed contaminated with mycotoxins and factors affecting their appearance on the field before harvest or during the storage of silage. Filamentous fungi can grow on grasses and are commonly found in silage or hay. Typically, there are three most important pre-harvest toxigenic genera - Aspergillus, Fusarium, and possibly Alternaria. Some Aspergillus species may appear before and after harvest (Jedidi et al., 2018). The appearance of these mushrooms in the field is associated with many factors, including agricultural methods and climatic conditions. Most of the mushrooms can be destroyed during the ensiling process (De Mattos-Shipley et al., 2016; Bellettini et al., 2019). However, there are other species, such as Aspergillus fumigatus, Penicillium rosenbergii, Pseudomonas, Fusarium oxysporum, and Monascus, that can tolerate high levels of organic acids and carbon dioxide in addition to low oxygen utilization (Bellettini et al., 2019). During storage, oxygen is particularly present in certain parts of the silo or during the stages of feeding and aerobic spoilage; the penetration of oxygen can promote the growth of mold and the production of mycotoxins (Driehuis and Elferink, 2000). In high-quality silage, lactic acid bacteria can effectively suppress mold growth (Oliveira et al., 2014), but even a small increase in oxygen concentration can create suitable conditions for the growth of fungi such as Roquefort and Penicillium mirabilis (Schirmer et al., 2020). Indeed, if most of the acetic acid, lactic acid, and carbon dioxide is vaporized and oxygen is present, almost all filamentous fungi associated with the grain can grow under these conditions. It is reported that there is a significant difference between the presence of mycotoxins in harvested plant and the level of their concentrations in feed, which is probably caused by various environmental factors (such as meteorological conditions, agronomic practices, ensiling procedures, feed use, type of feeding, etc.) or the conditions of the laboratory where the analyses were carried out (sampling procedures, storage, and preparation of samples, applied methods of analysis, etc.) (Daou et al., 2021).

\section{Alternaria species}

Various Alternaria species, such as Agrobacterium alternata, Agrobacterium Platycladus, and Agrobacterium vines, are isolated from hay and silage. However, Streptococcus has recently been suggested to be a rare species, and most of the strains originally identified as this strain actually belong to the Tenuissima species group, Arborescens species group, or other Streptococcus species. These fungi produce various compounds, such as streptotoxin, cotoxin, allendiene, tendontoxin, and tenazolic acid, with recognized toxicity (Omotayo et al., 2019). However, infectious Streptococcus can produce some other secondary metabolites such as 4Z-infected pyrrolidone, neopentane-arginine, dehydrotraveline, adoxyadreneric acid, or alternative endioic acid (Dellafiora and Dall'Asta, 2016). There are only a few reports of these compounds found in nature and fodder. The prevalence of toxins is reported to be high in various fodders, such as hay and silage, and their concentrations sometimes exceed $1000 \mu \mathrm{g} / \mathrm{kg}$. The authors analyzed these mycotoxins using a nonspecific screening method, which consists of a direct competitive enzyme immunoassay and detects the mycotoxins produced by Streptomyces. However, only one strain of Aspergillus arborescens has been confirmed to be involved in the production of toxins, while none of the other 98 identified strains of $A$. arborescens or other alternative strains produce these toxins.

\section{Aspergillus}

Mycotoxins of Aspergillus produced in fodder have been found in silage products (such as high-moisture corn). The most important mycotoxins produced by these organisms are AF (AFB1, AFB2, AFG1, and AFG2). Sometimes the content of these toxins in fodder is high, which leads to an increase in the consumption of AFB1 by lactating dairy cows (Sserumaga et al., 2020). However, the AF obtained from growing crops may be unevenly distributed in the field and, when sampled, they may reflect the AF location or may not reflect the AF distribution in the silo. Consequently, the measurement reliability is strongly influenced by the protocol used to collect representative samples, prepare samples for analysis, or isolate and quantify mycotoxins. Due to the uneven distribution of AF and all mycotoxins, the variability associated with the mycotoxin testing procedure is usually highly dependent on the sample design. For these aspects, the European Commission has developed sampling and analysis methods for the official control of mycotoxin levels in food or grains and animal feed. At present, the authorities have not taken any action to establish specific sampling procedures for hay or silage. Other mycotoxins produced by $A$. flavus and other Aspergillus species are kojic acid, cyclopyrazole, and $\beta$ nitropropionic acid.

\section{Aspergillus fumigatus}

A. fumigatus is one of the main toxin-producing fungi that affect feed in warm conditions. According to available data, there is a risk of related toxins, especially in silage, and it can produce more than 226 potential biologically active secondary metabolites (Phokane et al., 2019). Among these, dextran toxin is undoubtedly the most toxic metabolite, and the most frequent analysis shows that fumonisin metabolites are present in silage. However, it is generally thought to be produced during infection in mammals. Glial toxins are reported to be mainly produced on substrates with a low C:N ratio, 
thus, this is not a good indicator for the presence of $A$. fumigatus. It is believed that the low occurrence of gliotoxin in the feed samples is related to this aspect. Unfortunately, most of the other compounds of this fungus have not been tested in silage. It has recently been discussed that some mycotoxins derived from $A$. fumigatus, such as gliotoxin, fumitremorgin $A$, and paclitaxel A and C, are not present in feed samples in Russia. Colloidal toxins, glycolic acid, and microalgae are reported to be stable during the storage of feed, while fumagillin is unstable under silage conditions. Agroclavin and festuclavin are other mycotoxins that can be produced by $A$. fumigatus.

\section{Cyclopiazonic acid}

Cyclopiazonic acid, a toxic indolic tetra-acid, was first isolated from Penicillium cinerea and then from other species of Penicillium, A. flavus and A. oryzae. Since this toxin can also be produced by $A$. flavus, it is thought to coexist with AF and $\beta$-nitropropionic acid. Only a few studies have been conducted on the presence of cyclopyrazinic acid in feed. Studies have shown that contamination of feed with this mycotoxin can exceed $1000 \mu \mathrm{g} / \mathrm{kg}$. Several fungi of the genus Aspergillus and Penicillium can produce mycotoxins, including A. niger, A. niger, A. freisenii, A. carbonus, Pseudomonas verrucosa, and $P$. nordicus. Many authors did not find mycotoxins in feed, primarily because these fungi cannot tolerate high concentrations of acetic acid and $\mathrm{CO}_{2}$.

\section{Mycotoxin species and feed contaminations}

Among mycotoxins obtained from Fusarium, mucormycins A and B are produced by several species (Mabuza et al., 2018). Among the B-type trichothecenes, the most studied mycotoxins are nelphenol and fulsaladon $X$, as well as their acetylated and deacetylated analogs. They are mainly produced by $F$. culmorum and $F$. graminearum. These mycotoxins are considered to be the most common in silage and other fodder, and they can be present at varying stages of the disease. In particular, it has been reported that the prevalence of nelphenol in fodder exceeds $80 \%$, and the level of moderate contamination varies greatly, but it exceeds $2000 \mu \mathrm{g} / \mathrm{kg}$ in some cases. The nelphenol concentration measured at the top of the batcher was higher than that at the bottom.

Nelphenol content ranged from $100 \%$ to $13 \%$ in harvested corn (Góral et al., 2019), while the average neonaphthyl alcohol concentration in the hay was $131 \mu \mathrm{g} / \mathrm{kg}$, and the frequency of occurrence was $4 \%$. Finally, it is reported that approximately $20 \%$ of the corn kernels were contaminated with fuchsadon $X$ with a content of less than $5 \mu \mathrm{g} / \mathrm{kg}$. Mycotoxins, such as bisacetoxyconiferyl alcohol, T-2, and HT-2 toxins as well as their deacetylated analogs, are type A of trichosporone toxins, mainly composed of F. poae, F. sporotrichioides, and F. langsethiae. Although some authors report that these trichomoniasis are usually found during silage making, the average concentration is usually considered very low. T-2 toxin was not detected in hay and corn, as bisacetoxyconiferyl alcohol and its acetylated compounds are mainly produced by $F$. proliferatum and $F$. verticillioides, and pre-harvest crops are often infected. Among FBs, FB1 is the most important and most studied one. The FB1 presence is reported to be over $30 \%$ in hay samples, while it is lower in silage. Approximately $50 \%$ of the hay and silage were contaminated with FB1, and its average concentration was $120 \mu g$ of FB1 per $1 \mathrm{~kg}$ of fodder. Other FBs have also been found in corn, such as FB2 and FB3, but the contamination levels are very low. On average, $52 \%$ of the harvested grain was infected with FB, and the average infection rate was less than 500 $\mu \mathrm{g} / \mathrm{kg}$. FB was found in $43 \%$ of silage (Brodal et al., 2016). Other toxins derived from Fusarium, such as povirectin, olefinic acid, and monimodine, have been found in silage as well, but their contamination levels are very low. It is assumed that the decomposition process that occurs during the storage process is not confirmed.

\section{Penicillins}

Penicillins belong to the Penicillium rosenbergii family, such as Macrobrachium rosenbergii and Beauveria bassiana, and are considered one of the most common fungi in silage. Various key factors, such as unfavorable weather or storage conditions, can contribute to the growth of fungi and the production of mycotoxins. A list of the main mycotoxins produced by Penicillium strains is presented elsewhere (Rezende et al., 2013). There is no doubt that these mycotoxins are the most studied ones and are found in fodder. Plasmodium roqueforti was isolated from a silo containing $89 \%$ obviously moldy. Likewise, $P$. roqueforti and Pseudomonas pannus were isolated from $96 \%$ of maize stored in silos.

Penicillin Roquefort Toxin (PR toxin) is a mycotoxin produced by Macrobrachium rosenbergii that has been found in several types of fodder. About 76\% PR contamination with toxins in 63 feed samples (i.e. 25 hay and 38 silage and compound feed) is reported with an average contamination level of $130 \mu \mathrm{g} / \mathrm{kg}$. However, the method used is a low specific immunochemical screening method and the series of studies were unable to confirm the detected level of this mycotoxin. Mycophenolic acid and rofotin are considered the most studied Penicillium derivatives in silage products. The first is produced by $M$. rosenbergii and $B$. nivae and is found in the hay with different frequencies: about $40 \%, 30 \%, 10 \%$, or less than $3 \%$. In addition, the concentration of mycophenolic acid is reported to be in excess of $20,000 \mu \mathrm{g} / \mathrm{kg}$. Among the Rockfordins produced by various strains of Pseudomonas sports, the most studied one is Rockfordine C, which is found in over $40 \%$ of silage samples. However, Rockfordine $C$ has been reported to cause a low incidence. It was found that the average level of silage contamination with rophostin $C$ was $778 \mu \mathrm{g} / \mathrm{kg}$, the average level of contamination with mycophenolic acid was $524 \mu \mathrm{g} / \mathrm{kg}$, and the highest contamination levels were 3160 and $2630 \mu \mathrm{g} / \mathrm{kg}$, respectively. The other five types of Rocfortines were found in two of five samples. The average concentration was 100-1000 $\mathrm{\mu g} / \mathrm{kg}$. With regard to these mycotoxins, many authors (Moncini et al., 2020) reported that the frequency and concentration of 
mycotoxins collected from peripheral granaries were higher than those in the main granaries. Other Penicillium metabolites have also been found in silage, e.g. androgen A, citrulline isocoumarin, and matrine A, which are the biomarkers of Penicillium. It is known that two out of every five collected corn samples were infected with $N$. sylvestris, and festulavin was produced by Penicillium strains at concentrations ranging from 100 to $1000 \mu \mathrm{g} / \mathrm{kg}$. The frequency of occurrence of androgen A, citrulline isocoumarin, and marcfortine A is reported to be less than $20 \%$. Patulin produced by $P$. panum and $B$. nivae with a concentration of $10-1210 \mu \mathrm{g} / \mathrm{kg}$ is found in $23 \%$ of selected grain samples. Currently, there is no information on other toxins of the genus Penicillium (for example, the diploid protein of Botrytis) (Haque et al., 2020).

\section{CONCLUSIONS}

Existing data indicate that some streptoxins (aflatoxin, aspergillus toxin, aspergillus A toxin, fumonisin, and zearalenone) and many other secondary metabolites produced by many other types of Alternaria are harmful to ruminants. Tavronic acid and 4Z-infected pyrrolidone have the greatest effect on ruminants, A. flavus produces kojic acid, cyclopyrazinic acid, or $\beta$-nitropropionic acid, and A. fumigatus produces gliotoxin. Pseudomonas produces mycophenolic acid, Rocfortine, PRtoxin, Marcoforthine, or Monasc (citrine and monacolin); they may be associated with feed contamination. Thus, the types of mycotoxins, their prevalence, and their negative impacts on the storage of feed and the health of farm animals have been studied here.

\section{DECLARATIONS}

\section{Corresponding author \\ E-mail: ulrikh.e.v@mail.ru}

\section{Authors' contributions}

Both of authors participated in this review equally.

\section{Competing interests}

The authors declare that they have no competing interests.

\section{Ethical Regulation}

The review is written based on international ethical ensures and copyrights.

\section{REFERENCES}

Agriopoulou S, Stamatelopoulou E, Varzakas T (2020). Advances in occurrence, importance, and mycotoxin control strategies: Prevention and detoxification in foods. Foods, 9: 137. DOI: https://doi.org/10.3390/foods9020137

Azevedo JL, Maccheroni JW, Pereira JO, and De Araújo WL (2000). Endophytic microorganisms: a review on insect control and recent advances on tropical plants. Electronic Journal of Biotechnology, 3(1): 15-16. Link: https://scielo.conicyt.cl/scielo.php?pid=S0717-34582000000100004\&script=sci_arttext\&tIng=n

Bellettini MB, Fiorda FA, Maieves HA, Teixeira GL, Ávila S, Hornung PS, and Ribani RH. (2019). Factors affecting mushroom Pleurotus spp. Saudi Journal of Biological Sciences, 26(4): 633-646. DOI: https://doi.org/10.1016/j.sjbs.2016.12.005

Bennett JW, and Klich M (2003). Mycotoxins. Clinical Microbiology Reviews, 16(3): 497-516. DOI: https://doi.org/10.1128/CMR.16.3.497-516.2003

Brodal G, Hofgaard IS, Eriksen GS, Bernhoft A, Sundheim L (2016). Mycotoxins in organically versus conventionally produced cereal grains and some other crops in temperate regions. World Mycotoxin Journal, 9(5): 755-770. DOI: https://doi.org/10.3920/WMJ2016.2040

Bryden WL (2012). Mycotoxin contamination of the feed supply chain: Implications for animal productivity and feed security. Animal Feed Science and Technology, 173(1-2):134-158. DOI: https://doi.org/10.1016/j.anifeedsci.2011.12.014

Buckley T, Creighton A, and Fogarty U (2007). Analysis of Canadian and Irish forage, oats and commercially available equine concentrate feed for pathogenic fungi and mycotoxins. Irish Veterinary Journal, 60(4): 1-6. DOI: https://doi.org/10.1186/2046-0481-60-4-231

Conte G, Fontanelli M, Galli F, Cotrozzi L, Pagni L, and Pellegrini E (2020). Mycotoxins in Feed and Food and the Role of Ozone in Their Detoxification and Degradation: An Update. Toxins, 12(8): 486. DOI: https://doi.org/10.3390/toxins12080486.

Daou R, Joubrane K, Maroun RG, Khabbaz LR, Ismail A, and El Khoury A (2021). Mycotoxins: Factors influencing production and control strategies. AIMS Agriculture and Food, 6(1): 416-447. DOI: https://doi.org/10.3934/agrfood.2021025

De Mattos-Shipley KM, Ford KL, Alberti F, Banks AM, Bailey AM, and Foster GD (2016). The good, the bad and the tasty: the many roles of mushrooms. Studies in Mycology, 85: 125-157. DOI: https://doi.org/10.1016/i.simyco.2016.11.002

Dellafiora L, and Dall'Asta C. (2016). Masked mycotoxins: An emerging issue that makes renegotiable what is ordinary. Food Chemistry, 213: 534-535. DOI: https://doi.org/10.1016/j.foodchem.2016.06.112

Driehuis F, and Elferink SO (2000). The impact of the quality of silage on animal health and food safety: a review. Veterinary Quarterly, 22(4): 212-216. DOI: https://doi.org/10.1080/01652176.2000.9695061 
Firduas, R.B.R., Gunaratne, M.S., Rahmat, S.R., Kamsi, N.S., Yildiz, F. (2019). Does climate change only affect food availability: What else matters? Cogent Food and Agriculture, 5(1): 1707607. DOI: https://doi.org/10.1080/23311932.2019.1707607

Gallo A, Giuberti G, Frisvad JC, Bertuzzi T, and Nielsen KF (2015). Review on mycotoxin issues in ruminants: occurrence in forages, effects of mycotoxin ingestion on health status and animal performance and practical strategies to counteract their negative effects. Toxins, 7(8): 3057-3111. DOI: https://doi.org/10.3390/toxins7083057

Góral, T., Łukanowski, A., Małuszyńska, E., Stuper-Szablewska, K., Buśko, M., Perkowski, J. (2019). Performance of winter wheat cultivars grown organically and conventionally with focus on Fusarium head blight and Fusarium trichothecene toxins. Microorganisms, 7: 439. DOI: https://doi.org/10.3390/microorganisms7100439

Haque MD, Wang Y, Shen Z, Li X, Saleemi MK, He C (2020). Mycotoxin contamination and control strategy in human, domestic animal and poultry: A review. Microbial Pathogenesis, 142: 104095. DOI: https://doi.org/10.1016/j.micpath.2020.104095

Hussain T, Saleemi MK, Khan MZ, Khan A, Abbas RZ, Bilal MQ, Deeba F, Irshad H, Fatima Z, Afzal F, Farooq U (2020). Toxicopathological effects of endosulfan in female Japanese Quails (Coturnix japonica). Advancements in Life Sciences, 7(2):72-78. http://www.als-journal.com/articles/vol7issue2/721.20/866.pdf

Hussein HS, and Brasel JM (2001). Toxicity, metabolism, and impact of mycotoxins on humans and animals. Toxicology, 167(2): 101-134. DOI: https://doi.org/10.1016/S0300-483X(01)00471-1

Jedidi I, Soldevilla C, Lahouar A, Marín P, González-Jaén MT, and Said S (2018). Mycoflora isolation and molecular characterization of Aspergillus and Fusarium species in Tunisian cereals. Saudi Journal of Biological Sciences, 25(5): 868874. DOI: https://doi.org/10.1016/j.sjbs.2017.11.050

Mabuza LM, Janse van Rensburg B, Flett BC, Rose LJ (2018). Accumulation of toxigenic Fusarium species and Stenocarpella maydis in maize grain grown under different cropping systems. European Journal of Plant Pathology, 152: 297-308. DOI: https://doi.org/10.1007/s10658-018-1475-y

Medina A, Akbar A, Baazeem A, Rodriguez A, Magan N (2017). Climate change, food security and mycotoxins: Do we know enough? Fungal Biology Reviews, 31(3): 143-154. Dol: https://doi.org/10.1016/i.fbr.2017.04.002

Meggs WJ (2009). Epidemics of mold poisoning past and present. Toxicology and industrial health, 25(9-10): 571-576. DOI: https://doi.org/10.1177/0748233709348277

Moncini L, Sarrocco S, Pachetti G, Moretti A, Haidukowski M, Vannacci G (2020). N2 controlled atmosphere reduces postharvest mycotoxin risk and pests attack on cereal grains. Phytoparasitica, 48: 555-565. DOI: https://doi.org/10.1007/s12600$\underline{020-00818-3}$

Nesic K, Ivanovic S, and Nesic V (2014). Fusarial toxins: secondary metabolites of Fusarium fungi. Reviews of Environmental Contamination and Toxicology, Springer, Cham. 228: 101-120. DOI: https://doi.org/10.1007/978-3-319-01619-1_5

Oki Y, Soares N, Belmiro MS, Junior AC, and Fernandes GW (2009). The influence of the endophytic fungi on the herbivores from Baccharis dracunculifolia (Asteraceae). Neotropical Biology and Conservation, 4(2): 83-88. D0I: https://doi.org/10.4013/5119

Oliveira PM, Zannini E, and Arendt EK (2014). Cereal fungal infection, mycotoxins, and lactic acid bacteria mediated bioprotection: From crop farming to cereal products. Food Microbiology, 37: 78-95. D0I: https://doi.org/10.1016/j.fm.2013.06.003

Omotayo OP, Omotayo AO, Mwanza M, Babalola 00 (2019). Prevalence of mycotoxins and their consequences on human health. Toxicological Research, 35: 1-7. DOI: https://doi.org/10.5487/TR.2019.35.1.001

Phokane S, Flett BC, Ncube E, Rheeder JP, Rose LJ (2019). Agricultural practices and their potential role in mycotoxin contamination of maize and groundnut subsistence farming. South African Journal of Science, 115(9/10): 1-6. D0I: https://doi.org/10.17159/sajs.2019/6221

Pleadin J, Frece J, and Markov K (2019). Mycotoxins in food and feed. Advances in Food and Nutrition Research, 89: $297-345$. DOI: https://doi.org/10.1016/bs.afnr.2019.02.007

Porter JK (1995). Analysis of endophyte toxins: fescue and other grasses toxic to livestock. Journal of Animal Science, 73(3): 871-880. DOI: https://doi.org/10.2527/1995.733871x

Rezende EF, Borges JG, Cirillo MA, Prado G, Paiva LC, Batista LR (2013). Ochratoxigenic fungi associated with green coffee beans (Coffea arabica L.) in conventional and organic cultivation in Brazil. Brazilian Journal of Microbiology, 44(2): $377-384$. DOI: https://doi.org/10.1590/S1517-83822013000200006

Schirmer BCT, Sørheim O, Skaar I, Kure CF (2020). The Influence of Concentrations of Carbon Dioxide and Residual Oxygen on the Growth of Meat Spoilage Moulds. HSOA Journal of Food Science and Nutrition, 6: 064. DOI: http://dx.doi.org/10.24966/FSN-1076/100064

Scott $P$ (2009). Ergot alkaloids: extent of human and animal exposure. World Mycotoxin Journal, 2(2): 141-149. DOI: https://doi.org/10.3920/WMJ2008.1109

Sserumaga JP, Ortega-Beltran A, Wagacha JM, Mutegi CK, Bandyopadhyay R (2020). Aflatoxin-producing fungi associated with pre-harvest maize contamination in Uganda. International Journal of Food Microbiology, 313: 108376. DOI: https://doi.org/10.1016/j.ijfoodmicro.2019.108376

Vedovatto MG, Bento AL, Kiefer C, Souza KMR, and Franco GL (2020). Mycotoxins in the diet of beef cattle: a review [Micotoxinas na dieta de bovinos de corte: revisão]. Archivos de Zootecnia, 69(266): 234-244. Link: https://www.uco.eu/ucopress/az/index.php/az/article/view/5119

Zain ME (2011). Impact of mycotoxins on humans and animals. Journal of Saudi chemical society, 15(2): 129-144. DOI: https://doi.org/10.1016/i.jscs.2010.06.006 